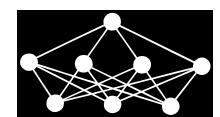

\title{
MODELING OF SMART CITY BUILDING BLOCKS USING MULTI-AGENT SYSTEMS
}

\author{
M. Lom*, O. Přribyl
}

\begin{abstract}
Technology has undergone rapid development in the past several decades and we are now at a point where many technologies are available to help create smart cities. Many technology companies and research institutions as well as political organizations are currently discussing this field with the highest priority. One can say that the biggest challenge to smart cities is not technologies themselves, but the merging of all available technologies into one symbiotic unit that fulfills the expected objectives. Smart cities are about connecting subsystems, sharing and evaluating data, and providing quality of life and satisfaction to citizens. We have various models of transportation systems, optimizations of energy usage, street lighting systems, building management systems, urban transport optimizations, however currently, such models are dealt with separately. In this paper, we provide an overview of the smart city concept and discuss why Multi-agent systems are the right tool for the modeling of smart cities. The biggest challenge is in connecting and linking particular subsystems within a smart city. In this paper, a modeling of a smart city building blocks is provided and demonstrated with one particular example - a smart street lighting system. Focus will be on the decomposition of the system into subsystems as well as a description of particular modules. We propose to build models and since each individual entity can be modeled as an agent with its beliefs, desires and intentions, we suggest using Multi-agent systems as a tool for modeling systems ${ }^{6}$ connections within the smart city and assessing how best to use the data from those systems.
\end{abstract}

Key words: multi-agent systems, smart cities, Belief-Desire-Intention

Received: October 27, 2016

DOI: $10.14311 / \mathrm{NNW} .2017 .27 .018$

Revised and accepted: August 30, 2017

\section{Introduction}

The human race stands on the threshold of a new age where a large part of our reality is transmitted into the virtual world. Proof of this transformation is the movement of direct human contact to social networks or the ability to perform certain types of jobs from the comfort of a home without daily presence in a workplace [2,11]. All of this transformation has been enabled by the Internet, which has connected the whole

\footnotetext{
* Michal Lom - Corresponding author; Ondřej Přibyl; Czech Technical University in Prague, Faculty of Transportation Sciences, Konviktská 20, CZ-110 00 Praha 1, Czech Republic, E-mail: lommicha@fd.cvut.cz, pribylo@fd.cvut.cz
} 
world and accelerated the transmission, sharing, and exchanging of information and data. The Internet has enabled the interconnections of products, services, and people into one virtual world through the Internet of Things (IoT), the Internet of Energy (IoE), the Internet of People (IoP), and the Internet of Service (IoS) [6].

All of these technologies will allow us to create a real-time overview of our cities and create a phenomenon of smart cities - where all services will be in a mutual symbiosis, where we can minimize waste and maximize energy efficiency. A municipal development will be led in the most optimal and the most sustainable way, crime will be almost zero and data from particular systems will be shared across a city to the benefit of residents and tourists. Specific data will be accessible to the public in order to provide a complete overview of their city. Since this whole concept is based on mining, processing, and sharing vast amounts of data (Big Data), it is necessary for a large part of our effort to be devoted to cyber security to minimize a misuse of such data. The creation of smart cities is an interdisciplinary field and requires a high degree of cooperation between experts from many different fields. The topic of smart cities cannot be seen only as a technical discipline, but also economic, humanitarian and legal aspects must be involved as well [10].

The main reasons for the emergence of the Smart City Initiative are to create a sustainable model for cities and preserve the quality of life of their citizens [13]. In 2050, the population of our planet will increase up to 10 billion according to the United Nations [27]. This article deals with one of the unresolved area of the smart city - how to model and how to handle different data from different systems throughout the smart city. The concept of Systems identity must be taken into consideration in modeling [12]. We discuss the possibility to use Multi-agent systems (MAS) as a tool for modeling subsystems of the smart city.

\section{Interconnecting systems}

If we want to create a sustainable city with emphasis on the quality of life, we need as much relevant data as possible from all the systems in order to take into account their optimal utilization to increase life comfort and satisfaction of citizens. According to the Czech environmental law, a sustainable model is: "A development that ensures for present and future generations the possibility of meeting their basic life needs while not reducing the diversity of nature and preserves the natural functions of ecosystems" [22]. To define the quality of life itself is very complicated, because the quality of life means something else for each of us. However, if we were to choose one definition, we would tend to [18]: "The quality of life is intangible aspects of life, i.e. health, social relationships, quality of the natural environment, existing living conditions and personal prosperity". There are different approaches how to measure the quality of life [19].

The general definition of a system according to [26], the system is a set of interacting or interdependent component parts forming a complex whole. Every system is delineated by its spatial and temporal boundaries, surrounded and influenced by its environment, described by its structure and purpose and expressed in its functioning. In case of the smart city, we can introduce a street lighting, a building or a road infrastructure as examples of the system. A subsystem is a relatively separated and identifiable part (component, element) of a system [21]. A lamp 
Lom M., Přibyl O.: Modeling of smart city building blocks using...

is a subsystem of a public lighting system, a room is a subsystem of a building, a crossroad is a subsystem of a road infrastructure or human is a fundamental subsystem of a social system. In this paper, the term (inter)connecting means information connections between systems or subsystems.

Interconnecting systems is a very complicated area, because many various variables are presented and goals of systems are different and often contradictory. It is very important to find a balance among the goals of system and to ensure that the interconnection of different systems will converge to improvement of the quality of life of citizens. It is important to note that interconnection must take into consideration existing communication standards [28].

Imagine that we want to build a shopping center in a part of a city where any center was not before. What impact will this new building have on the traffic in the neighborhood of the shopping center? Modeling, prediction and measurement tools of the traffic are relatively good and we can predict what the impacts will be [23]. What impact will this building have on the economy of the district? It can be assumed that the shopping center will create new job positions in the area and the district will profit from the taxes that the shopping center will pay to them. On the other hand, it can happen that the shopping center will reduce the profit of small local shops, some of which may eventually disappear. What will happen to the comfort of residents living close to such a shopping center? Residents can be happy about the fact that they will no longer have to travel to distant shopping centers and that can be time-saving for them. However, if such a center stands near residential areas, we can assume that this center will attract many visitors (traveling by cars, public transportation, etc.), which will considerably reduce the tranquility of the area. In addition, there is the evidence that shopping centers attract for example homeless or teenage social activities which means raise of potential for increased security problems [14]. Another problem is that the shopping center increases criminality in the area, because of the fact that people come here to spend their money, which of course attracts thieves [9]. What happens if we build that shopping center instead of a park or some favorite place for people living close? Where does the distance lie that people prefer to take the convenience of shopping instead of traveling?

As we can see from the example above, large number of variables from different disciplines enter this project. In terms of the smart city it is not possible to look for such structures only from the perspective of various disciplines, but it is essential to view it comprehensively. There are intersecting fields from technology, economics, environment protection, public governance to humanities. It is necessary to have a coordination among disciplines from the very beginning (design stage). The approach, when we see a building just as a construction of a building is outdated and therefore inapplicable on the smart city. Every part of the Smart City Initiative should benefit from any such projects.

If we look at Fig. 1, we see that for example in terms of Smart Mobility the impact of transportation on the construction site or effective parking (e.g. using mobile applications) must be resolved. If we look at the project in terms of Smart Governance, then we see that the city district would have the benefit from taxes paid by stores or that the shopping center could be used for organizing charity collections, or developers should meet a condition that in the area some playgrounds 


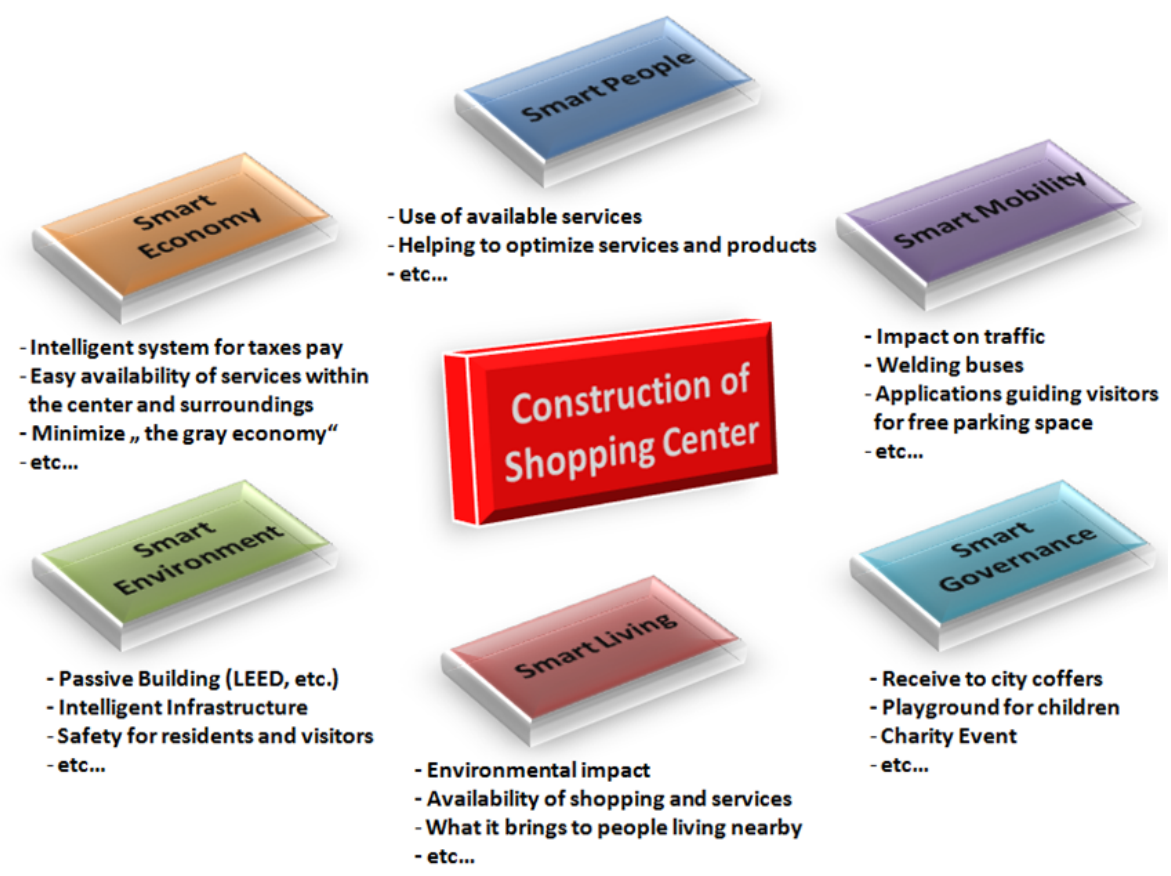

Fig. 1 Construction of shopping center in a smart city (own source).

or green areas have to be built.

An important part is Smart People, who should profit from the advantages offered by this district using the available services, products and opportunities that are offered. Another very important part is the feedback from them in order to improve and optimize services and products.

\section{Multi-agent systems and smart cities}

What we lack are software models that would allow us to model connections/ interconnections of systems/subsystems across the smart city. It does not only concern buildings and their impacts on the city and residents but also general modeling interconnections of individual subsystems that should work independently and reciprocally share data that could help the optimal operation of these subparts within the smart city. How can we traffic data utilize to improve the quality of life? How can we facilitate a government oversight of its citizens and companies without restrictions of the freedom of residents? How to improve the safety and the quality of life? How to use energy production using the Smart Grid in the best way? There are so many options in the city how to make the city of higher quality and safer place that is difficult to start anywhere. This can be one of the most important reasons, why the Smart City Initiative is still at the beginning. It is necessary to join many different fields and even for scientific and top technological companies it is hard to start from the right point of the view. Therefore, we suggest starting 
with modeling of systems interconnections.

For this reason, we propose to use Multi-agent systems (MAS) as a fundamental tool for modeling interconnections of systems/subsystems and modeling situations that may arise within the smart city. Every product and human can be modeled as an intelligent agent with its beliefs, desires and intentions. It means that we can easily compose systems of the smart city independently and then seek for the links among individual systems in dynamic ways because MAS is not a static concept as well as the smart city. For example, we can easily model a smart phone with its properties as an agent, we can add services or people that influence environment and we can see what happens and maybe we can find some new rules that are not obvious at first sight.

The smart city is a dynamic, non-deterministic, and asynchronous system. There is no "big brother", a centralized point that controls the whole city. The smart city is a distributed architecture and we should take the example from the Nature all around us. In the Nature, there is no central brain that would control our lives or our decisions. Every person on the planet is one agent and the same concept should be applied on architectures of the smart city. People as well as devices should work autonomously and with a good balance to achieve their goals and be the most beneficial to their surroundings.

Although MAS is the well-known modeling tool and it is used in many different areas, not so many papers about modeling smart cities using MAS have been published so far $[5,8]$. In the next section, we would like to stress the suitability of MAS for modeling smart cities.

\section{Building blocks}

Because of the fact that the smart city is dynamic, non-deterministic environment with many variables, we need to define simplified building blocks and divide the smart city into them. The smart city consists of many building blocks as buildings, lighting, transportation etc. A building block can be simply perceived as a block with inputs and outputs that shall fulfill some given objective(s). The inputs and outputs are basically communication interfaces that can transmit and receive information among themselves through a communication network (e.g. via Internet) [4].

The inputs to the system are frequently the outputs of some other systems, and the outputs of the system are used as the inputs to other systems. It must be mentioned that the smart city shall not be seen as a standard hierarchical model [24]. For example, similarly to the hierarchical traffic control models of a city with the lowest level corresponding to the local intersection controller, area control level coordinating more intersections, city control level and typically a national traffic control/information system. Every building block should be seen as an agent with an individual behavior in the environment and the agents can be mutually influenced.

In Fig. 2, the examples of building blocks as agents within a concept of a smart street are shown [15]. A sensor, a smart phone, a car, a trash can or an information board are examples of agents in the smart city. These agents can communicate together and interconnect systems/subsystems into a functional whole. We must 
not forget that the smart city does not only include sensors and actuators, but technologies are tools to achieve goals of the Smart City Initiative.

It is crucial to stress that each building block must have its own internal logic and operate autonomously even if the inputs from other systems are not available (e.g. because of communication failure). It means that the whole architecture is based on distributed intelligence [20].

In order to make the search for the interrelationships between building blocks simpler, we propose to build models using MAS. In the next section, we deal with the creation of BDI model for a smart street lamp.

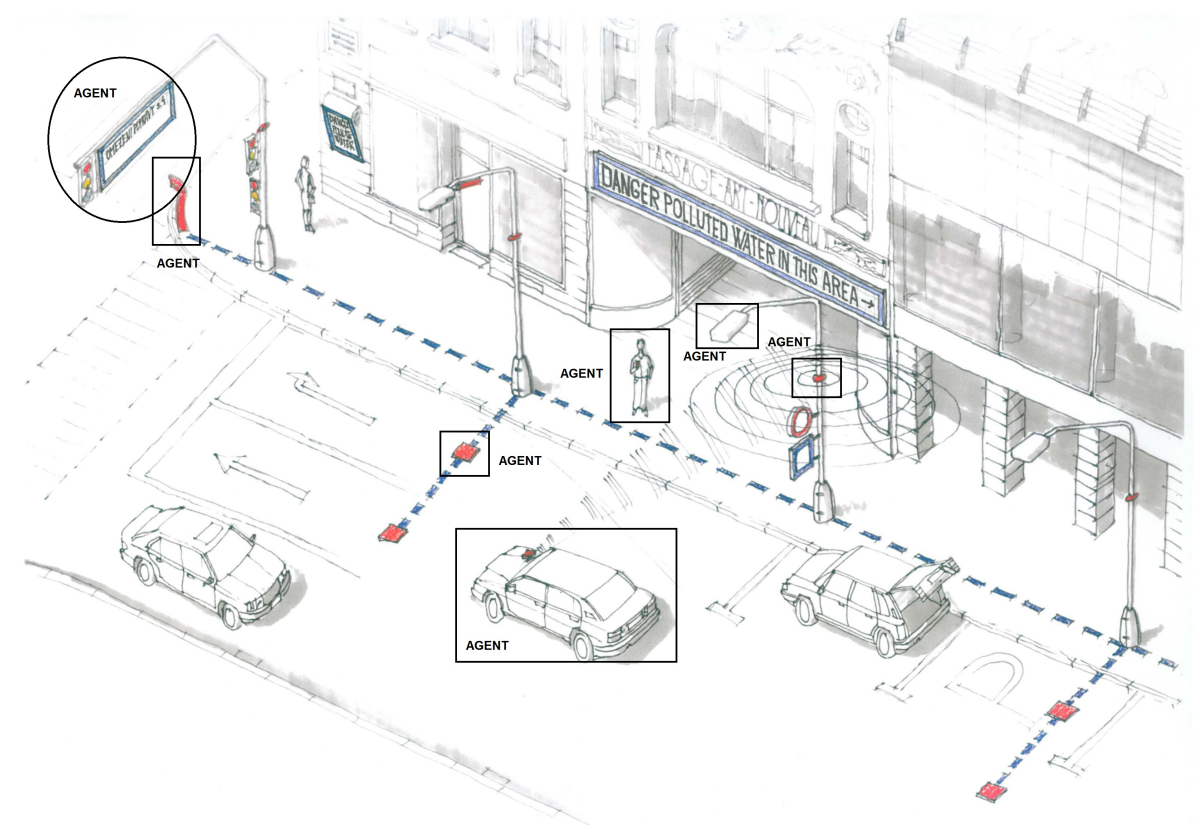

Fig. 2 Building block, agent based concept of a smart street (own source, author: O. Hykš).

\section{Smart city as a Belief-Desire-Intention model}

Many different architectures for intelligent agents modeling exist and many of them are discussed, for example [16,25]. Four basic types of agent architectures are logic-based, reactive, belief-desire-intention, and layered.

In Logic-based approach decision making is viewed as a deduction. The agent's decision making strategy is encoded as a logical theory, and the process of selection an action reduces to a problem of a proof. Logic-based approaches are sophisticated, and have clean (logical) semantics. But logic-based approaches have many disadvantages. In particular, the inherent computational complexity of theorem proving makes it questionable whether the agents as theorem provers can operate effectively in time-constrained environments. Decision making in such agents is predictable on 
Lom M., Přibyl O.: Modeling of smart city building blocks using...

the assumption of calculative rationality - the assumption that the world will not change in any significant way while the agent is deciding what to do, and that an action, which is rational when decision making begins, will be rational when it concludes. The problems associated with representing and reasoning for complex, dynamic, possibly physical environments are also essentially unsolved [1].

On the other hand, advantages of reactive approaches are simplicity, economy, computational tractability, robustness against failure, and sophistication that all make such architectures appealing. But there are some fundamental, unsolved problems. If agents do not employ models of their environment then they must have sufficient information available in their local environment for them to determine an acceptable action. Since purely reactive agents make decisions based on local information, (i.e., information about the agents current state), it is difficult to see how such a decision making could take into account non-local information - it must inherently take a "short term" view. It is difficult to see how purely reactive agents can be designed to learn from experience, and improve their performance within time. A major selling point of purely reactive systems is that overall behavior emerges from the interaction of the component behaviors when the agent is placed in its environment. But the very term "emerges" suggests that the relationship among individual behaviors, environment, and overall behavior is not understandable. This necessarily makes it very hard to engineer agents to fulfill specific tasks. Ultimately, there is no principled methodology for building such agents: one must use a laborious process of experimentation, trial and error to engineer an agent $[16,25]$.

Layered architectures represent a natural decomposition of functionality: it is easy to see how reactive, pro-active, social behavior can be generated by reactive, pro-active, and social layers in an architecture. The main problem with layered architectures is that while they are arguably a pragmatic solution, they lack the conceptual and semantic clarity of unlayered approaches. In particular, while logic-based approaches have clear logical semantics, it is difficult to see how such semantics could be devised for a layered architecture. Another issue is interactions among layers. If each layer is an independent activity producing process then it is necessary to consider all possible ways the layers can interact with other ones [17].

BDI architectures are practical reasoning architectures, in which the process of deciding what to do resembles the kind of practical reasoning that we use in our everyday lives. The basic components of a BDI architecture are data structures representing the beliefs, desires, and intentions of the agent, and functions that represent its deliberation (deciding what intentions to have - i.e., deciding what to do) and means-ends reasoning (deciding how to do it). Intentions play a central role in the BDI model: they provide stability for decision making, and act to focus the agent's practical reasoning. A major issue in BDI architectures is the problem of striking a balance between being committed to and over-committed to one's intentions: the deliberation process must be finely tuned to its environment, ensuring that in more dynamic, highly unpredictable domains it reconsiders its intentions relatively frequently - in more static environments, less frequent reconsideration is necessary. The BDI model is attractive for several reasons. Firstly, it is intuitive we all recognize the processes of deciding what to do and then how to do it, and we all have an informal understanding of the notions of belief, desire, and intention. Secondly, it gives us a clear functional decomposition, which indicates what sorts 
of subsystems might be required to build an agent. Because of these advantages, we decided to choose BDI architecture for modeling. But we are aware of the fact that the main difficulty, as ever, is to know how to implement these functions efficiently [25].

The different types of an environment require different types of decision strategies. In static, unchanging environment, purely pro-active, goal directed behavior is adequate. But in more dynamic environments, the ability to react to changes by modifying intentions becomes more important. It is completely the same situation in the smart cities. We need to take into account that there are many different types of environments and we must consider which type of intelligent agents should be used in order to meet requirements and achieving goals in the fastest and most effective way [25].

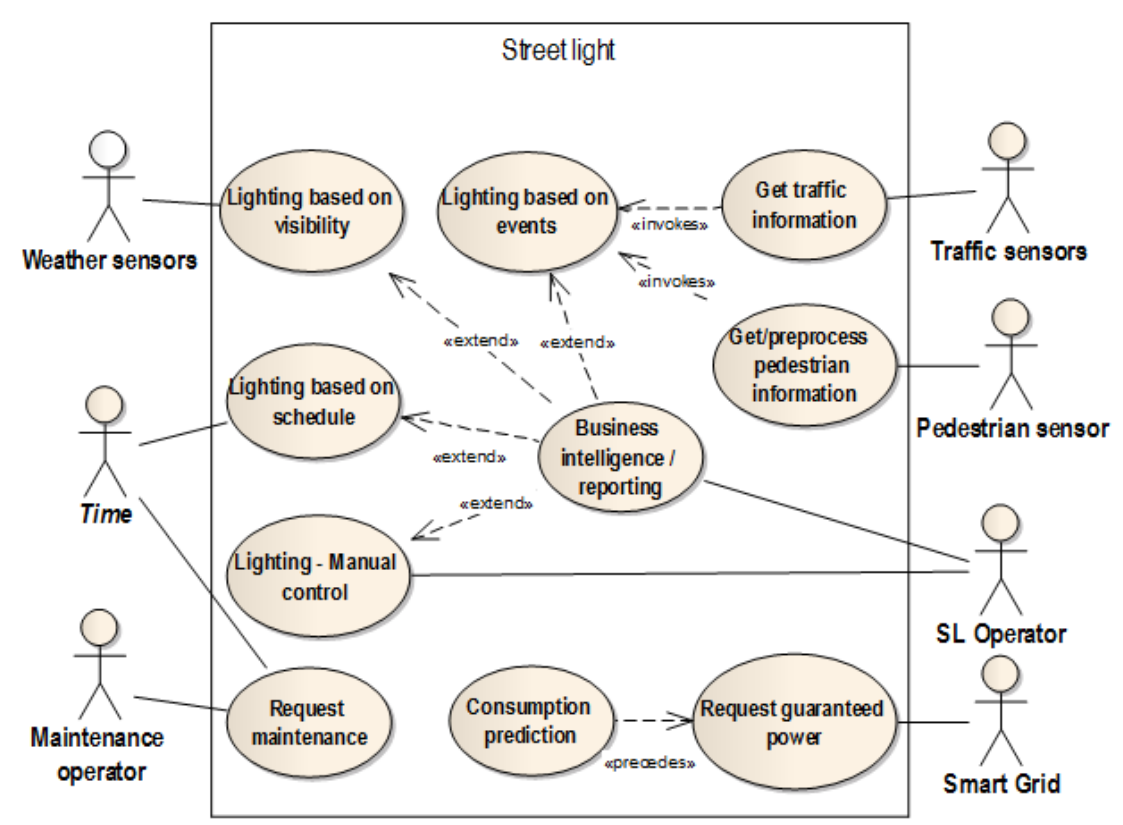

Fig. 3 Lamp's Use Case Diagram using UML (own source).

In this paper, we chose a smart street lamp for BDI modeling. Lamps are located in most of the streets in a city, they are typically owned by a municipality, they are not easily accessible and they also stand close to all major city building blocks (buildings, vehicles, bins, etc.) at the same time. The interconnection of street lamps can also be seen as a base for telecommunication infrastructure and serve as a data collector from systems located in the street and these data can be forwarded to other systems or vice versa. 
Lom M., Přibyl O.: Modeling of smart city building blocks using...

Before we will define the beliefs, desires and intentions, we propose to create a use case diagram of a modeling agent using UML (Unified Modeling Language). UML can be used as a tool for designing behavior diagrams that emphasizes what must happen in the system being modeled. Since behavior diagrams illustrate the behavior of a system, they are used extensively to describe the functionality of software systems [7]. As an example the use case diagram describes a user's interaction with the system that shows how users or adjacent systems (in the UML jointly denoted actors) interact with the system.

In Fig. 3, we can see the use case diagram of a smart street lamp. We can see actors who are involved in the interaction with the system and individual use cases related to the lamp. There are basically four different modes of operation: lighting based on a predefined schedule, lighting based on sensors measuring current visibility, lighting based on events on the road, such as presence of vehicles or pedestrians and manual control, when an operator is responsible for turning the street lights on and off. Apart from the current control of the lighting power or the mode of operation, the diagram shows a prediction model of power consumption, which is used for power request from a smart grid in advance. The use case requests proactive maintenance service based on regular time interval or based on parameters of the lamp (such as decrease in performance) and finally the use case with business logic is able to provide reporting services.

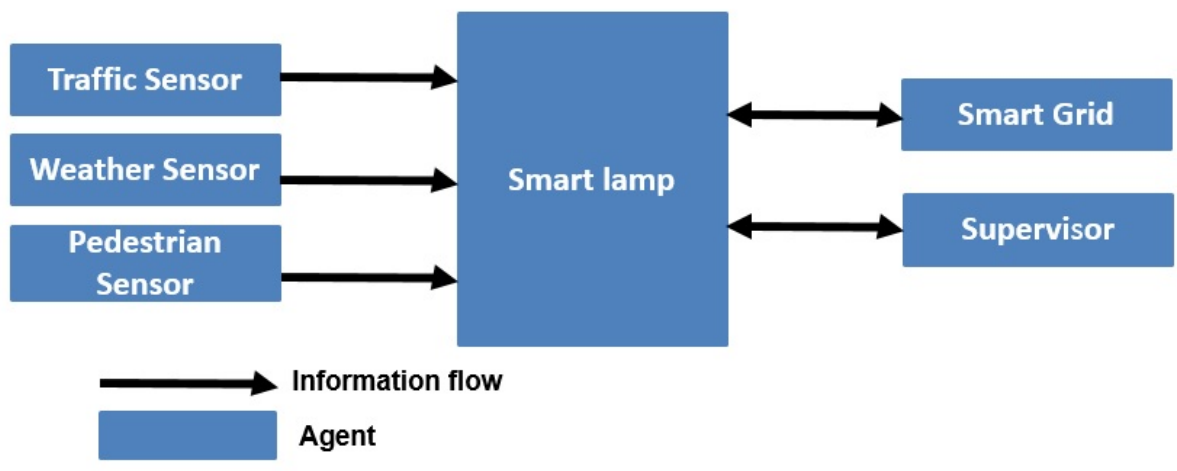

Fig. 4 Implemented BDI model (own source).

A use case diagram is very comfortable for the description of the behavior of a system and it is a very good tool for clarifying the behavior of the system on different level of perception - management as well as technical one. It is a base for further system analysis and decomposition. From the modeling point of view, the lamp is the agent with its beliefs, desires and intentions. For the description of lamp's BDI, we used the pseudo language of JASON based on Java that can be used for implementation of BDI models [3]. The implemented BDI model is shown in Fig. 4. The actors Time, Maintenance operator and SL Operator (shown in Fig. 3) are merged into one agent called Supervisor for simplification.

The basic sequence diagram, which focuses on the message interchange among a number of agents, is shown in Fig. 5. The traffic, weather and pedestrian sensors communicate only one-way. They send data about their status directly to the 


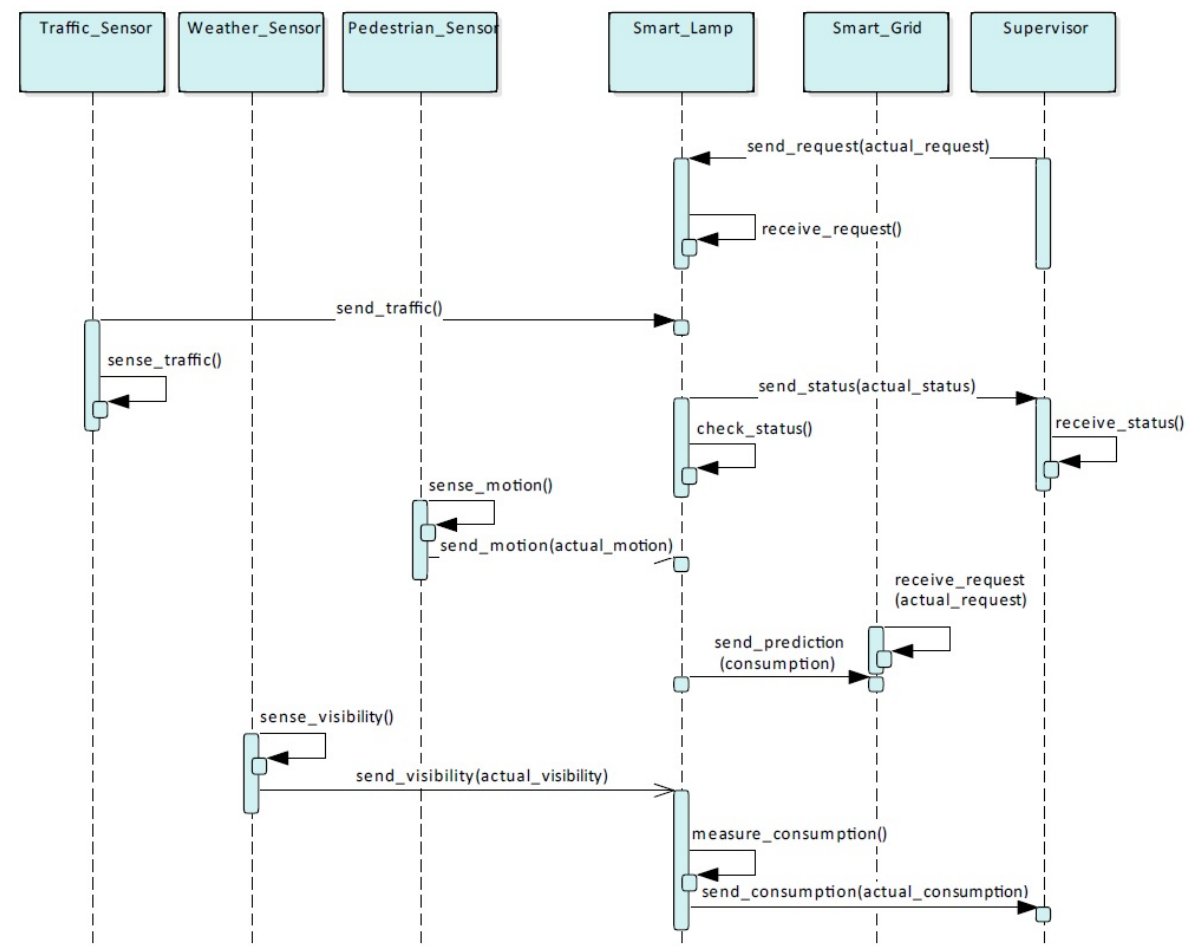

Fig. 5 Sequence diagram of communication (own source).

smart lamp. They cannot receive any messages. On the other hand, the smart lamp can communicate in two ways and can receive some commands from the supervisor and send data to the supervisor. The communication itself is based on invocation of classes as shown in the sequence diagram. The detailed explanation of communication based on BDI architecture is described below.

\subsection{Beliefs of a Smart Street Lamp}

Beliefs represent the informational state of an agent, in other words its beliefs in the world (including itself and other agents). Beliefs can also include inference rules, allowing forward chaining to lead to new beliefs [25].

The beliefs of the lamp are an initial performance (init_perf in Fig. 6) after being put into operation. The performance indicates the current brightness of the lamp. Another beliefs are the maximum performance (max_perf), initial consumption (init_consumption), initial status (init_status) after being put into operation and status, when everything is right and there is no need for service maintenance (good_status). The set of beliefs is called a belief base.

It is important to say that beliefs may change during "the life". It means that some of beliefs can disappear or accrue depending on an environment and interact with other agents. 
Lom M., Přibyl O.: Modeling of smart city building blocks using...

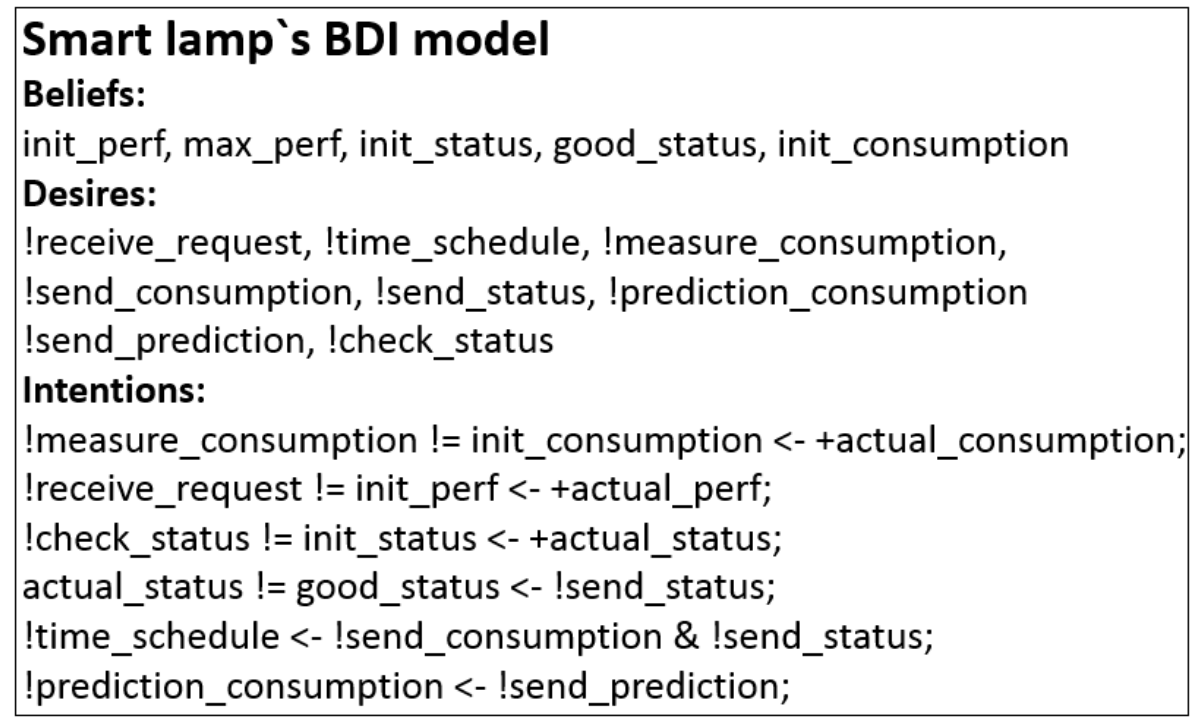

Fig. 6 Smart Lamp`s BDI Model (own source).

\subsection{Desires of a Smart Street Lamp}

The desires represent the motivational state of an agent. They represent objectives or situations that the agent would like to accomplish or bring about. The examples of desires can be: to find the best price, go to a party or become rich. A goal is a desire that has been adopted for active pursuit by the agent. The use of the term goals adds a further restriction saying that the set of active desires must be consistent [25].

The desires of the lamp are to receive requests (!receive_request in Fig. 6), measure consumption (!measure_consumption), send information about its consumption and status (! send_consumption, !send_status), predicate its consumption (!prediction_consumption) and send this prediction to the smart grid (!send_prediction), check its status (!check_status; e.g. if maintenance is required) and fulfill actions according to a time schedule (!time_schedule). The request can be received from other systems (e.g. weather sensor, pedestrian sensor, traffic sensor or smart grid). The lamp triggers corresponding intentions (actions) which are based on these requests.

\subsection{Intentions of a Smart Street Lamp}

The intentions represent the deliberative state of an agent - what the agent has chosen to do. The intentions are desires to which the agent has to some extent committed and represent the know-how of a program (the knowledge about how to do things, which is used to reach the agents goals). In implemented systems this means that the agent has begun to execute a plan. Plans are sequences of actions (recipes or knowledge areas) that an agent can perform to achieve one or more of its intentions [25]. 
The intentions of the lamp are described in Fig. 6. The intentions have two distinct parts: the triggering event (condition) and the body. The two parts are syntactically separated by "<-". Triggering events are related to two types of changes in the agent's mental attitude: changes in beliefs and changes in the agent's goals. They are used for checking the current situation to determine a particular plan is likely to succeed in handling the event (e.g. achieving a goal). The body of an intention is a sequence of formula determining a course of an action to be performed by the agent when an event that matches the plan's triggering event has happened and the context of the plan is true in accordance with the agent's beliefs.

For instance, the intention !measure_consumption != init_consumption <+actual_consumption means that the body of the intention (actual_consumption) is added to the lamp's belief base, when !measure_consumption is changed and distinguished from init_consumption. Further, the intention !receive_request != init_perf <- +actual_perf means that after receiving a request from other agents, a change is invoked in the initial performance (the lamp changes its brightness and performance) and the new belief actual_perf has to be added to the belief base. The next intention actual_status != good_status <- !send_status means that the actual status indicates a failure and the lamp needs to be maintained by a maintenance operator. The message is sent to a maintenance center. The intention !time_schedule <- ! send_consumption \& !send_status implies that information about the actual consumption and status of the lamp are sent to relevant authorities according to a time schedule.

\subsection{Other agents interacting with the lamp}

The lamp interacts with other lamps and also receives information from the weather sensor, pedestrian sensor, traffic sensor and smart grid. BDI models of these agents are shown in Fig. 7.

In Fig. 7, the weather sensor has the beliefs regarding a visibility in environment - an initial visibility (init_visibility) and minimum visibility for triggering action (min_visibility). The desires are to sense the visibility in the environment and send information about the current visibility ! send_visibility. The intention ! sense_visibility != init_visibility <- +actual_visibility means that the body of the intention is to add the belief actual_visibility to the sensor's belief base, when !sense_visibility is changed and distinguished from init_visibility. The second intention is invoked when actual_visibility is less or equal to min_visibility. The sensor sends a request to the lamp, which receives them via an intention !reiceve_request. The same approach as described in the sections above is applied on other devices in Fig. 7.

\section{Conclusion}

In this paper, we discuss the modeling of the smart city using BDI architecture. We claim that the decomposition into particular building blocks must occur and we also point out the suitability of agent-based modeling for this task. In order to work with the building blocks in a coherent way, the system decomposition must be performed and a systematic approach should be adopted. In this paper, we 
Lom M., Přibyl O.: Modeling of smart city building blocks using...

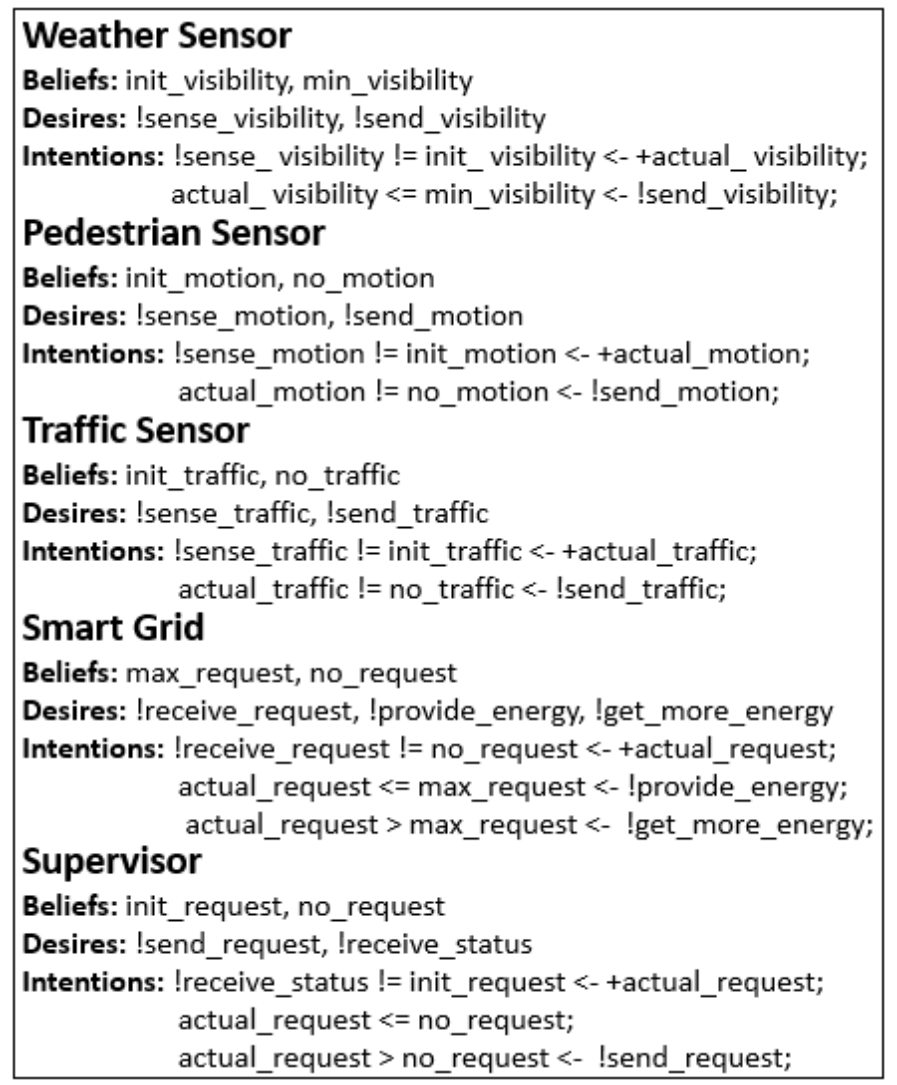

Fig. 7 BDI Model of other agents (own source).

demonstrate the approach on one of particular building blocks of a smart city smart street lamps. Firstly, the scope and interactions are described. Next, a use case analysis is performed and a description for the smart street lamp model is presented. The use case analysis is further enhanced through the model of beliefs, desires and intentions of a smart lamp as needed to build up a Multi-agent system of the belief-desire-intention type. The same procedure is used for modeling other devices within the model.

\section{Acknowledgement}

This work was supported by the Czech Technical University in Prague under project no. SGS16/185/OHK3/2T/16.

\section{References}

[1] ATKInSON K., BENCH-CAPON T., McBURNEY P. A Dialogue Game Protocol for MultiAgent Argument over Proposals for Action. Autonomous Agents and Multi-Agent Systems. 2005, 11(2), pp. 153-171. doi: :10.1007/s10458-005-1166-x. 
[2] BARUCH Y. Teleworking: benefits and pitfalls as perceived by professionals and managers. New Technology, Work and Employment 15.1. 2000, pp. 34-49.

[3] BORDINI R.H., HUBNER J.F., WOOLRIDGE M. Programming Multi-Agent Systems in AgentSpeak Using Jason. John Wiley \& Sons, 2007.

[4] CSISZÁR C., FÖLDES D. Analysis and Modelling Methods of Urban Integrated Information System of Transportation. Smart Cities Symposium, 24-25 June 2015. Prague, Czech Republic, pp. 1-10, doi: 10.1109/SCSP. 2015.7181574.

[5] GHOSN S.B., RANGANATHAN P., SALEM S., TANG J.P., LOEGERING D., NYGARD K.E. Agent-oriented designs for a self healing smart grid. Proceedings of First IEEE International Conference on Smart Grid Communications (SmartGridComm), Gaithersburg, MD, USA. IEEE, 2010. doi: 10.1109/SMARTGRID. 2010.5622085

[6] GUBBI J., BUYYA R., MARUSIC S., PALANISWAMI M. Internet of Things (IoT): A vision, architectural elements, and future directions. Future Generation Computer Systems. 2013, 29(7), pp. 1645-1660. doi: 10.1016/j.future.2013.01.010

[7] JACOBSON I., CHRISTERSON M., JONNSON P., ÖVERGAARD G. Object-Oriented Software Engineering - A Use Case Driven Approach, Addison-Wesley, 1992.

[8] KARNOUSKOS S., DE HOLANDA T.N. Simulation of a smart grid city with software agents. Computer Modeling and Simulation, 2009. EMS'09. Third UKSim European Symposium on. IEEE, 2009.

[9] KINNEY J.B., BRANTINGHAM P.L., WUSCHKE K., KIRK M.G, BRANTINGHAM P.J. Crime attractors, generators and detractors: land use and urban crime opportunities. Built Environment. 2008, 34(1), pp. 62-74.

[10] LOM M., PřIBYL O, ZELINKA T. Hybrid-Agile Approach in Smart Cities. Proceedings of the 20-th World Multi-Conference on Systemics, Cybernetics and Informatics, Volume I (2016), IIIS, Orlando, FL, USA, pp. 50-55, ISBN-13: 978-1-941763-43-8.

[11] MARCHE S. Is Facebook making us lonely. The Atlantic. 2012, 2.

[12] MOOS, P., SVÍTEK M., VOTRUBA Z. Smart cities, multi-system approach to system modelling, 2016 Smart Cities Symposium Prague (SCSP), Prague, 2016, pp. 1-6.

[13] MORI K., CHRISTOdOUlOU A. Review of Sustainability Indices and Indicators: Towards a New City Sustainability Index (CSI). Environmental Impact Assessment Review. 2012, 32, pp. 94-106.

[14] PITT M., MUSA Z.N. Towards defining shopping centres and their management systems. Journal of Retail \& Leisure Property. 2009, 8.1, pp. 39-55.

[15] PŘIBYL P., PŘIBYL O. Definition of a smart street as smart city's building element. In: Smart Cities Symposium Prague (SCSP), 24-25 June 2015, 2015, pp. 1-6.

[16] RAO A. S., GEORGEFF M.P. BDI Agents: From Theory to Practice. ICMAS. Vol. 95. 1995.

[17] RAO A.S., GEORGEFF M.P. Modeling rational agents within a BDI-architecture. KR, 1991, 91, pp. $473-484$.

[18] RIFKIN J. European dream. Prague: European literature club. 2005, 423pp.

[19] SCHALOCK R.L., ed. Quality of life. Vol. 2. Aamr, 1997.

[20] SU K., JIE L., HONGBO F., Smart city and the applications. Electronics, Communications and Control (ICECC), 2011 International Conference on. IEEE, 2011.

[21] SUBSYSTEM. [online] Business Dictionary. [viewed 2016-05-14]. Available from: http: //www. businessdictionary.com/definition/subsystem.html

[22] SUSTAINABLE DEVELOPMENT. §6 law no. 17/1992 Sb. Environmental law of the Czech Republic.

[23] TANG T.Q., CACCETTA L., WU Y.H., HUANG H.J., YANG X.-B. A macro model for traffic flow on road networks with varying road conditions. Journal of Advanced Transportation. 2014, 48(4), pp. 304-317. doi: 10.1002/atr.215

[24] VRANCKEN J., et al. A hierarchical network model for road traffic control. Networking, Sensing and Control, 2009. ICNSC'09. International Conference on. IEEE, 2009. 
Lom M., Přibyl O.: Modeling of smart city building blocks using...

[25] WEISS G. Multiagent systems. Second edition. Cambridge, Massachusetts: The MIT Press, 2013, xlviii, 867 pages. ISBN 9780262018890.

[26] WILSON B. Systems, concepts, methodologies, and applications. New York:Wiley, 1984. ISBN 0471904430.

[27] WORLD POPUlATION PROSPECTS: THE 2015 REVISION. United Nations, Department of Economic and Social Affairs, Population Division, 2015.

[28] ZELINKA T. C-ITS as Multidisciplinary Area with High Demand on Telecommunications Solutions. Journal of Systemics, Cybernetics and Informatics. 2014, 12(5), pp. 68-72. ISSN $1690-4524$. 